\title{
Ride Quality Investigation of Passenger Cars on Different Road Conditions
}

\author{
Se Jin Park, Murali Subramaniyam \\ Korea Research Institute of Standards and Science, Daejeon, 305-340
}

\begin{abstract}
Objective: The ride qualities of the six passenger cars were evaluated in 4 subjects on the highway and uneven road. The relation between vibration with driving velocity and driving posture were also investigated separately. Background: Ride comfort plays an important role in the vehicle design. Vibration is the one of the principal components associated with ride comfort. Method: The acceleration of the foot, hip and back were measured using B\&K accelerometers in this study. The velocity of the passenger cars was maintained at a constant speed of $80 \mathrm{~km} / \mathrm{h}$ on the highway and $40 \mathrm{~km} / \mathrm{h}$ on the uneven road. For evaluating the effects of driving velocity and driving posture on vehicle's vibration level, separate experiments were performed on the highway with 5 different vehicle speeds and 5 different backrest angles, respectively. Results: The overall ride value of the luxury car showed the best result while the smaller car showed the worst value on the highway. On the uneven road the overall ride value level was increased $75 \sim 98 \%$. All the vehicles had the SEAT value less than 1 . Faster the velocity lowers the SEAT value. The ride quality in terms of vibration gets worst when the backrest angle increased. Conclusion: The smaller car had a first mode at the higher frequency and showed higher vibration level. SEAT value was mostly affected by the seat property not by vehicle. We ranked the luxury car seat had a best vibration reduction quality than others based on SEAT values. When the driving velocity increased, the overall ride values were increased proportionally and the SEAT values were somewhat decreased. Application: Evaluation of whole-body vibration in the passenger car.
\end{abstract}

Keywords: Passenger car, Driving velocity, Driving posture, Ride values, Ride comfort, SEAT value, RMS, Vibration

\section{Introduction}

Recent years, cars have become the essential transporting tools in the modern life. Along with technological development and life-quality improvement, users have higher and higher demand for ride quality and car performance. Ride quality concerns the driving personnel's comfort (Park et al., 1997, 1998, 2001; Kim et al., 2001; Nahvi et al., 2006). The ride comfort plays an important role in the vehicle design. The vibration is one of the principal components associated with ride comfort (Reed et al., 1991; Park et al., 1997, 1998, 1998a, 2001; Paddan and Griffin, 2002; Nahvi et al., 2009; Lin et al., 2006). Vibration transmitted to the buttocks and back of the occupant along the vertebral axis via the base and back of the seat has a large influence on comfort, performance, and health; in particular the whole-body vibration plays an important role in it (Griffin, 1990, 1998).

The ride quality is inherently a subjective measure and

Corresponding Author: Se Jin Park. Korea Research Institute of Standards and Science, Daejeon, 305-340

Mobile: +82-10-5406-5450, E-mail: sjpark@kriss.re.kr

Copyright@2013 by Ergonomics Society of Korea(pISSN:1229-1684 eISSN:2093-8462). All right reserved.

(c) This is an open-access article distributed under the terms of the Creative Commons Attribution Non-Commercial License(http://creativecommons.org/licenses/by-nc/3.0/), which permits unrestricted non-commercial use, distribution, and reproduction in any medium, provided the original work is properly cited. http://www.esk.or.kr 
the perceived comfort levels are different for people even with the same stimulus (Park et al., 1998). To improve the ride quality, past studies were attempted to identify the factors contributing to the ride quality and to match the ride quality with the subjective feeling (Griffin, 1990; Parsons and Griffin, 1983; Pardko and Lee, 1966; Reed et al., 1991; Wambold, 1986; Valasek et al., 2008; Lin et al., 2006). Few studies were measured the vehicles ride qualities using the ride value (Wambold, 1986; Park et al., 1998, 2001; Kim et al., 2001).

The major components contributing to the ride quality of the vehicle are the tire, suspension, road conditions and seat. The optimization schemes have been developed to increase the ride quality with such design variables as the tire, suspension, and seat property (Berger and Gilmore, 1993; Amirouche et al., 1994; Nahvi et al., 2009; Lin et al., 2006). The important design considerations in the car seat development are human health (Kelsey, 1975; McLain and Weinstein, 1994; Necking et al., 1992; Troup, 1978) and comfort (Dupius and Zerlett, 1986; Griffin, 1990; Park et al., 1997, 1998a). The seat dynamics may become significant in the ride quality since the seat directly transmits the vibration to the passenger. Hence studies were measured the seat characteristics and improved the seat performance (Park et al., 1998; Fouladi et al., 2011; Paddan and Griffin, 2002). Seat vibrational comfort was evaluated by developing several experimental test methods (Giacomin and Bracco, 1995; Meier et al., 1998; Staszewski and Giacomin, 1997; Park et al., 2001).

The level of perceived vibration is different according to the frequency and the axis of vibration; the equivalent comfort contours based on the subjective rating were formed and adapted in ISO 2631 and BS 6841. Griffin suggested some ride values regarding that the level and duration of the root mean square acceleration of the whole-body is closely related with the subjective ride quality by frequency weighting functions which are the inverse of equivalent comfort curve (Griffin, 1990, 1998; Parsons and Griffin, 1983; Park et al., 1998, 2001; Nahvi et al., 2006, 2009).

In this study, we evaluated the ride qualities of the six passenger cars in 4 subjects on the highway and uneven road. The effects of variation in the driving velocity and driving posture on vibration were also investigated. Seat dynamics were investigated for the transmissibility in the seats and seat effective amplitude transmissibility (SEAT) value.

\section{Method}

\subsection{Experimental setup}

Whole-body vibration mainly transmitted through the seat surfaces, backrests, and through the floor to an individual sitting in the vehicle (Park et al., 1998). The experimental setup for measuring the whole-body vibration at the feet, hip and back is shown in Figure 1. The vibration was measured at 8 axes based on measuring scheme proposed in 1990 by Griffin. The measured axes - three translations $\left(X_{\mathrm{f}}, \mathrm{Y}_{\mathrm{f}}, \mathrm{Z}_{\mathrm{f}}\right)$ at feet, 3 translations $\left(\mathrm{X}_{\mathrm{s}}, \mathrm{Y}_{\mathrm{s}}, \mathrm{Z}_{\mathrm{s}}\right)$ of hip and two translations $\left(\mathrm{X}_{\mathrm{b}}, \mathrm{Z}_{\mathrm{b}}\right)$ of back. As of BS 6841, 12-axis measuring system is accepted in the vehicle industry. In this study, we have omitted four minor axes (3 rotations of hip and y-translation of the back), which showed a small contribution to the ride values (Park et al., 1998). The acceleration of the foot was measured by B\&K 4326 accelerometer and the accelerations of the hip and back was measured by B\&K 4322 accelerometer. The output signal was amplified through B\&K 8-channel charge amplifier Type 5974 and was recorded with $1 \mathrm{kHz}$ sampling rate by 16-bit digital recorder (Sony DAT 216A) (Park et al., 1998).

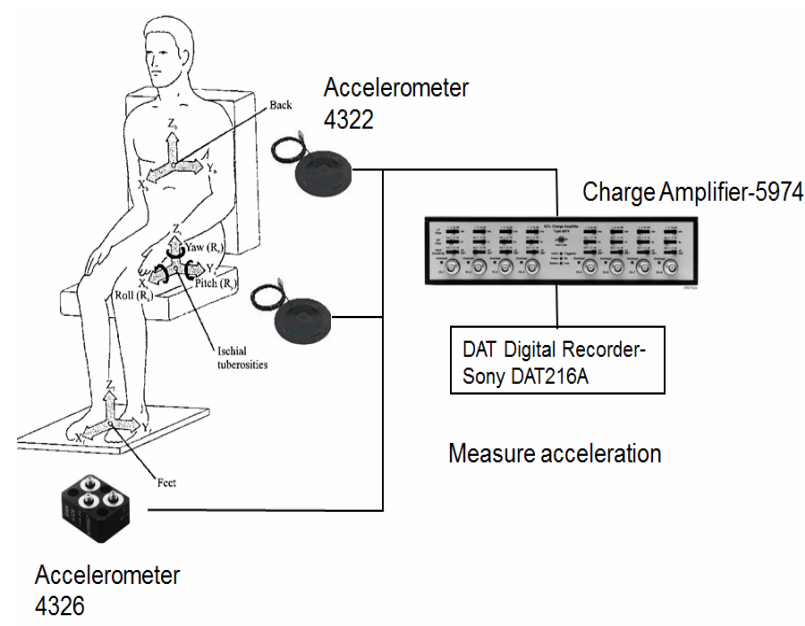

Figure 1. Schematic configuration for the measurement of whole-body vibration (Park et al., 1998)

The subjects were seated in the front passenger seat and 
the experimenter with the equipment was placed in the rear seat. The subjects sat on a B\&K 4322 3-axis translational sensor fastened on a seat cushion and another B\&K 4322 3 -axis translational sensor fastened on the backrest. The B\&K 4326 3-axis translational sensor was attached to the floor of the vehicle along with the global coordinate: foreand-aft as $\mathrm{x}$ direction, lateral as $\mathrm{y}$ direction and vertical as $\mathrm{z}$ direction.

\subsection{Experimental procedure}

This experiment was conducted for six vehicles (Table 1) on the highway and uneven road in the driving test field. Four subjects were participated in this experiment (Table 2). The velocity was maintained at a constant speed of $80 \mathrm{~km} / \mathrm{h}$ on the highway and $40 \mathrm{~km} / \mathrm{h}$ on the uneven road for keeping the same vibration condition of road. The experiments were repeated for 3 times at the same condition. Since the posture of the subject is important in measuring the human vibration, the backrest angle was fixed and the subjects were asked to keep their posture straight up during signal collection and not to fasten seat belt for the pure seat dynamics. This experiment executed for 1 week. So the road condition might have changed during the experiment. But this change was almost ignorable in highway and small in the uneven road.

Table 1. Characteristics of vehicles

\begin{tabular}{c|c|c}
\hline Vehicle & Displacement $(\mathrm{cc})$ & Type \\
\hline V1 & 800 & Passenger \\
\hline V2 & 1500 & Passenger \\
\hline V3 & 1800 & Passenger \\
\hline V4 & 2500 & Passenger \\
\hline V5 & 3000 & Passenger \\
\hline V6 & 5000 & Passenger \\
\hline
\end{tabular}

Table 2. Physical characteristics of subjects

\begin{tabular}{c|c|c}
\hline Subject & Height $(\mathrm{cm})$ & Weight $(\mathrm{kg})$ \\
\hline S1 (Female) & 156 & 48 \\
\hline S2 (Female) & 167 & 51 \\
\hline S3 (Male) & 173 & 68 \\
\hline S4 (Male) & 184 & 94 \\
\hline
\end{tabular}

The car vibration level in driving is much affected by the driving velocity. To test this factor, separate experiment was performed on the highway with variations in the driving velocity. The driving velocities considered were $60,70,80$, 90 and $100 \mathrm{~km} / \mathrm{h}$. We have asked all the subjects to remain constant in a comfortable posture during data acquisition. As explained earlier, the posture of the subject is important in measuring the human vibration. Generally people feel comfortable when they lean to the backrest with larger angle. To test this factor, separate experiment was performed on the highway by considering different sitting postures. The backrest angles considered were 10, 20, 25, 30 and $40^{\circ}$. In this case, the vehicle's velocity was maintained at $80 \mathrm{~km} / \mathrm{h}$.

\subsection{Data analysis}

The manner in which vibration affects health, comfort, perception and motion sickness is dependent on the vibration frequency content (Griffin, 1990). As ISO 2631 and BS 6841 indicated, the comfort rating was determined by means of the frequency weighting filters. We have considered 4 functions of frequency weightings $\left(\mathrm{W}_{\mathrm{b}}, \mathrm{W}_{\mathrm{c}}, \mathrm{W}_{\mathrm{d}}, \mathrm{W}_{\mathrm{e}}\right)$ and 8 -axis. The weighting functions and axis multiplying factors are described in BS 6841. Many researchers have tried to quantify the ride value and developed many ride values. In this study, we evaluate the ride values such as the component ride value, the overall ride value and the seat effective amplitude transmissibility (Parsons and Griffin, 1983; Griffin, 1990; Park et al., 1998; Kim et al., 2001).

\subsubsection{Component ride value}

The contribution of each axis can be quantified as the ride value according to the contact points between the human and the seat. The component ride value (CRV) is defined as the acceleration r.m.s value of each axis. These values are enabling to evaluate the relative contributions of each axis. The component ride value was obtained using the Eqn. (1).

$$
C R V_{i}=m_{i} \times \sqrt{\int P_{i i}(f) w_{i}(f)^{2} d f}
$$

Where, $\mathrm{m}_{\mathrm{i}}$ is the axis multiplying factor; $\mathrm{P}_{\mathrm{ii}}(\mathrm{f})$ is the power spectral density of each axis; $\mathrm{w}_{\mathrm{i}}$ is the weighting function of the each axis. 


\subsubsection{Overall ride value}

The overall ride value (ORV) is evaluated as the 2-norm of the CRV as Eqn. (2). The ORV gives the total vibration level; it is adequate for making simple comparisons between vehicles with different seat, suspension, etc. In the view of vibration, the seat with highest ORV expected to be the most uncomfortable seat.

$$
O R V=\sqrt{\left[\sum_{i=1}^{N}\left(\text { Component ride } \text { value }_{\mathrm{i}}\right)^{2}\right]}
$$

\subsubsection{Seat Effective Amplitude Transmissibility (SEAT) value}

SEAT value is defined as the weighted vibration ratio between $Z_{\mathrm{f}}$ of the floor and $Z_{\mathrm{s}}$ of the hip. SEAT value greater than 1 means the vibration at the seat is greater than the vibration at the floor, SEAT value lower than 1 indicates that the level of vibration is decreased by the seat (Griffin, 1990; Park, 1998; Kim, 2001). The seat effective amplitude transmissibility is given by Eqn. (3)

$$
S E A T=\sqrt{\frac{\int P_{s s}(f) w_{b}(f)^{2} d f}{\int P_{f f}(f) w_{b}(f)^{2} d f}}
$$

Where $\mathrm{P}_{\mathrm{ss}}(\mathrm{f})$ and $\mathrm{P}_{\mathrm{ffl}}(\mathrm{f})$ are the seat and floor acceleration power spectra, and $\mathrm{W}_{\mathrm{b}}$ is the same weighting function in both the numerator and denominator (Griffin, 1990; Niekerk et al., 2003). $\mathrm{W}_{\mathrm{b}}$ is the frequency weighting for the human response to vibration which is of interest: this is the weighting for vibration occurring on the seat and not the weighting for vibration on the floor.

\section{Results}

\subsection{Component ride value}

The RMS level of acceleration of each axis for the vehicles is presented (Figure 2). The vehicles CRV for each axis were calculated using Eqn. (1) and is presented (Figure. $3)$. We can see from the Figure 3 that three significant directions (foot-z, hip-z, and back-x) have larger magnitude of CRV than other directions and these three directions contributed to ORV about $80 \sim 90 \%$.

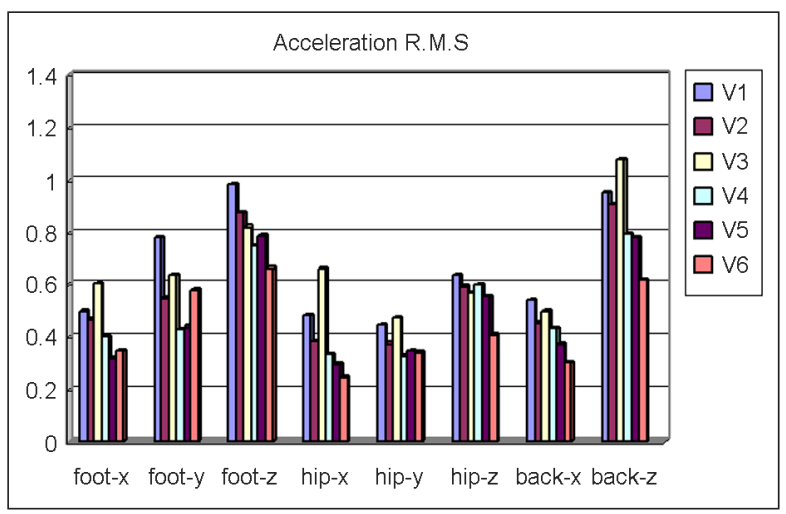

Figure 2. Acceleration R.M.S for 6 vehicles

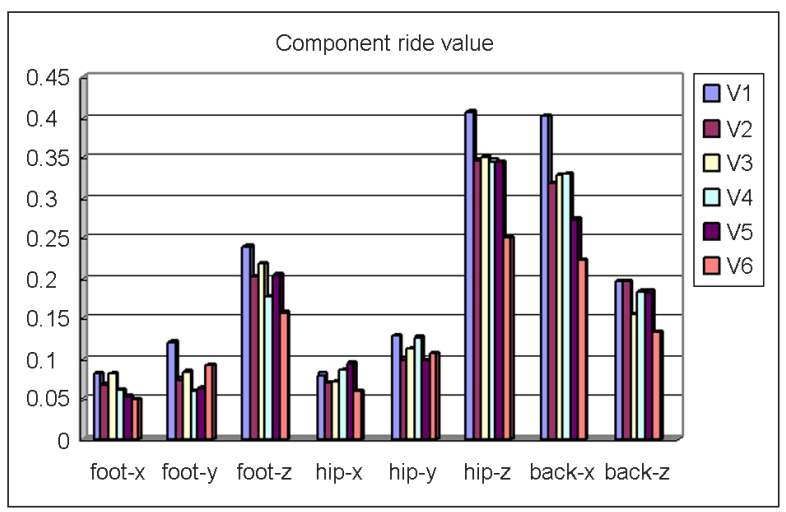

Figure 3. Component ride value for 6 vehicles

\subsection{Overall ride value}

The vehicles ORV were evaluated using Eqn. (2). The ORV for the subjects and vehicles is presented (Figure 4), which was obtained on a highway. On the highway the ORV were similar for four subjects in all the vehicles. Between vehicles, the ORV of the vehicle 1 was higher and the ORV of the vehicle 6 was lower. As explained earlier highest ORV represents the most uncomfortable seat. Vehicle 6 (luxury car) showed the best result while the vehicle 1 (small car) showed the worst ORV. Therefore, luxury car has most comfortable seat than small car.

The ORV for the two subjects and vehicles is presented 
(Figure 5), which was obtained in an uneven road. On the uneven road the ORV were similar to those of highway but the levels were increased by $75 \sim 98 \%$. Between vehicles, the vehicle 6 showed the smallest increase about $75 \%$ on the uneven road. Similar like driving on the highway, the luxury car showed the best result while the small car showed the worst ORV.

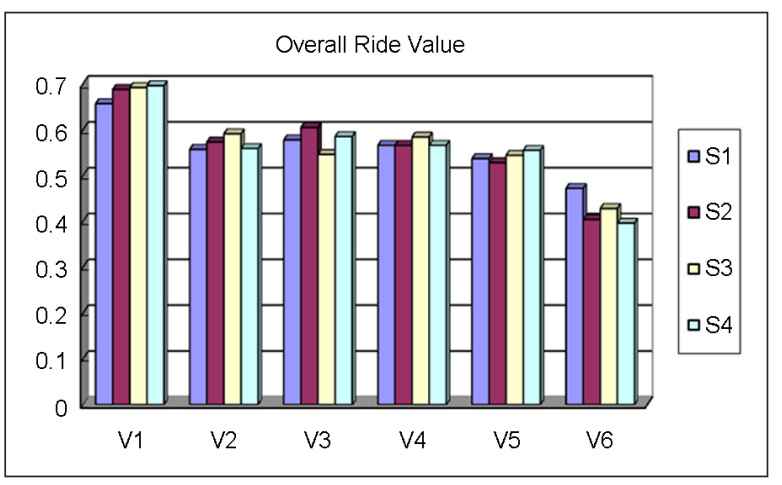

Figure 4. Overall ride values for 4 subjects and 6 vehicles on the highway

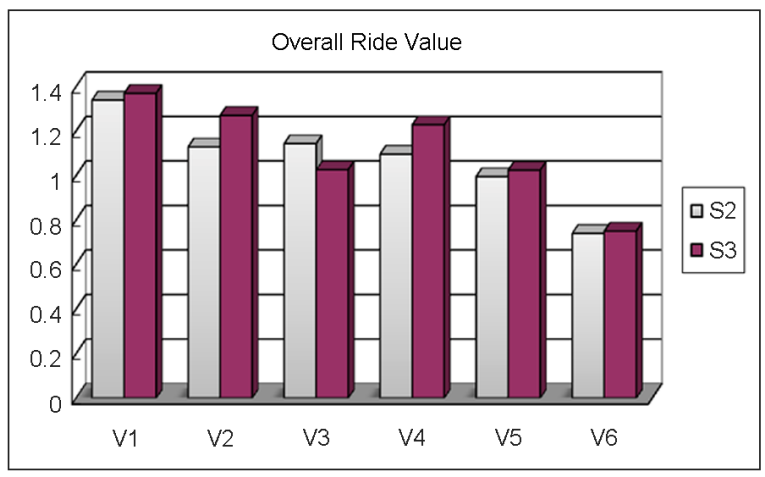

Figure 5. Overall ride value for 2 subjects and 6 vehicles on the uneven road

\subsection{SEAT value}

The SEAT values were evaluated using Eqn. (3) and represented in Figure 6 for the vehicles and subjects. From the Figure 6 we can't find the effect of the difference of subjects on SEAT value. Though so many other factors can influence the SEAT value, we can say that the seat of vehicle 6 had a best vibration reduction quality and the seat of vehicle 4 had the worst with the results of F-test with 5\% significance level. All vehicles had the SEAT value less than 1 , so vibration was reduced by the seats.

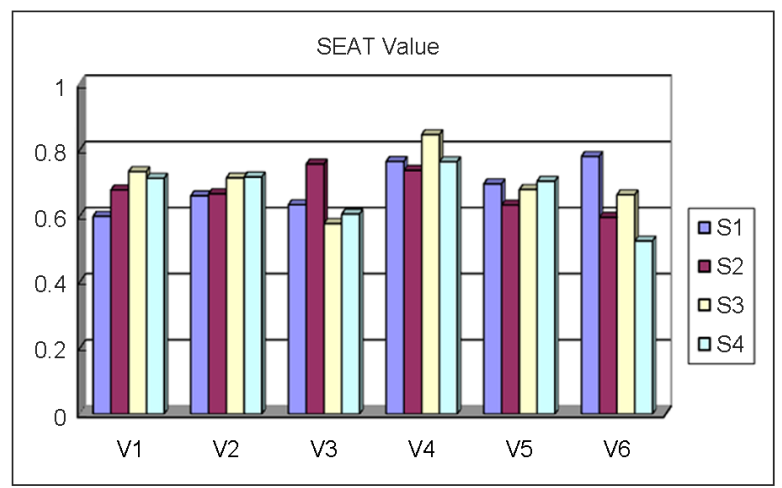

Figure 6. SEAT value for 4 subjects and 6 vehicles

\subsection{Relation between driving velocity and vibration}

The relation between driving velocity and vehicles vibration level were tested with different vehicle speed on the highway. The ORV and SEAT values were estimated to understand the effects of driving velocity on vibration level and the results are presented in Figure 7 and Figure 8, respectively. The ORV's of the vehicles were increased in proportion to the driving velocity. In terms of SEAT value, the values were decreased for the vehicles when the driving velocity increased. This was because the velocity affects the higher frequency more than the lower frequency and the seat easily damps the high frequency vibration.

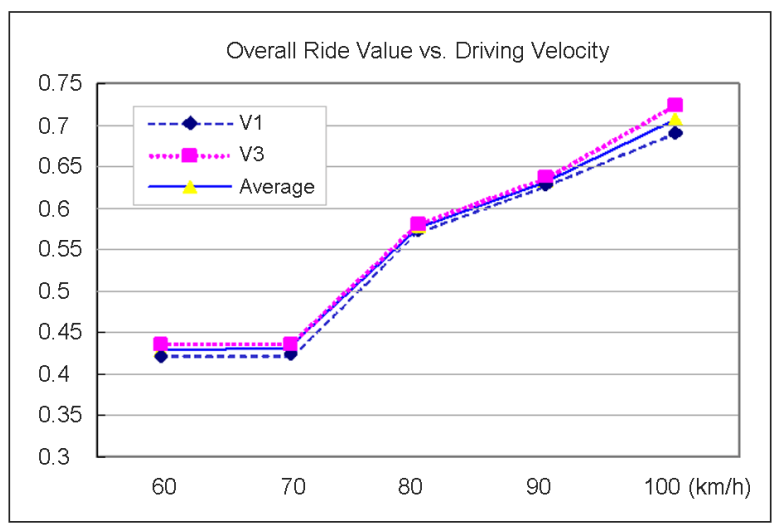

Figure 7. Overall ride value with respect to driving velocity 


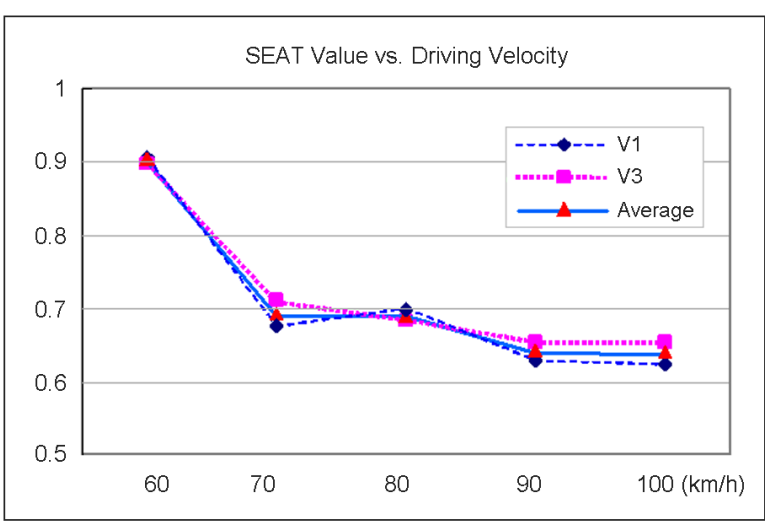

Figure 8. SEAT value with respect to driving velocity

\subsection{Relation between posture and vibration}

The relation between sitting posture and vehicles vibration level were tested with different backrest angles. The ORV and SEAT values were estimated to understand the effects and the results are shown in Figure 9 and Figure 10, respectively with the backrest angle varied from $10 \sim 40^{\circ}$ in 5 steps. The ORV and the SEAT values were somewhat increased with the increase of the backrest angle. These results clearly indicate that while driving with vibration most comfortable posture was sitting with smaller backrest angle. Even though people feel comfortable when they lean to the backrest with larger angle, in terms of vibration the case was different.

When the backrest angle increased the ride quality in terms of the vibration get worse. This effect represented in

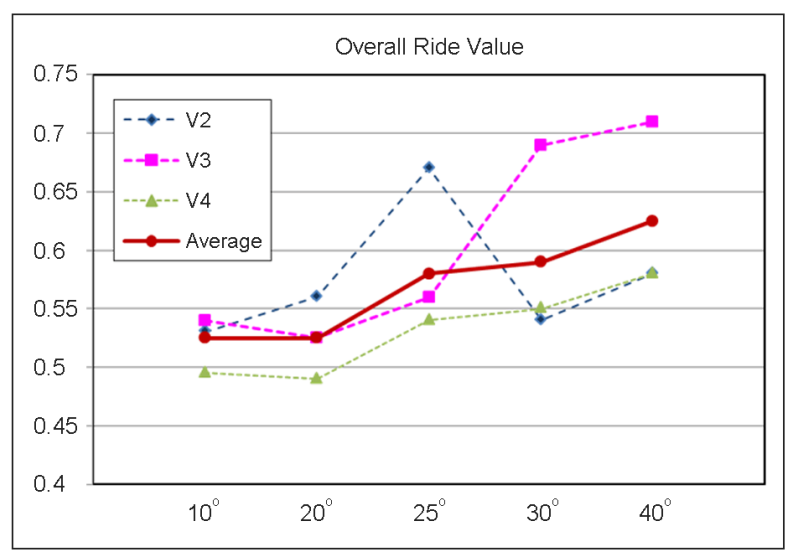

Figure 9. Overall ride value with respect to backrest angle

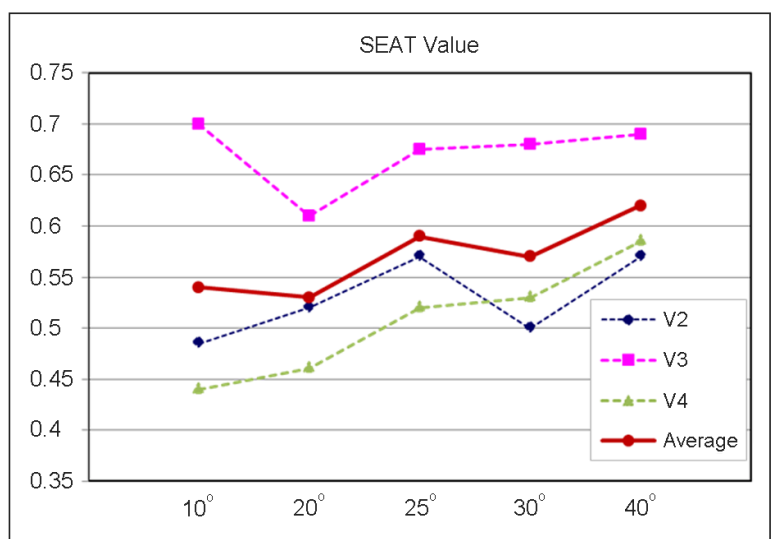

Figure 10. SEAT value with respect to backrest angle

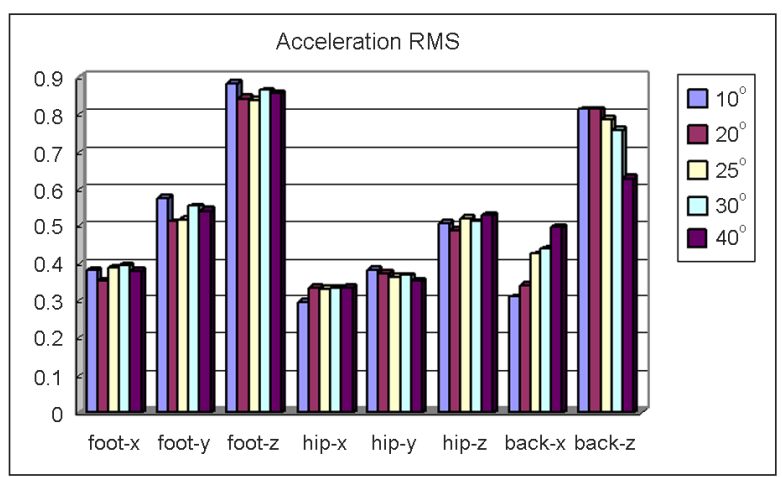

Figure 11. Overall ride value with respect to backrest an Acceleration RMS with respect to backrest angle gle

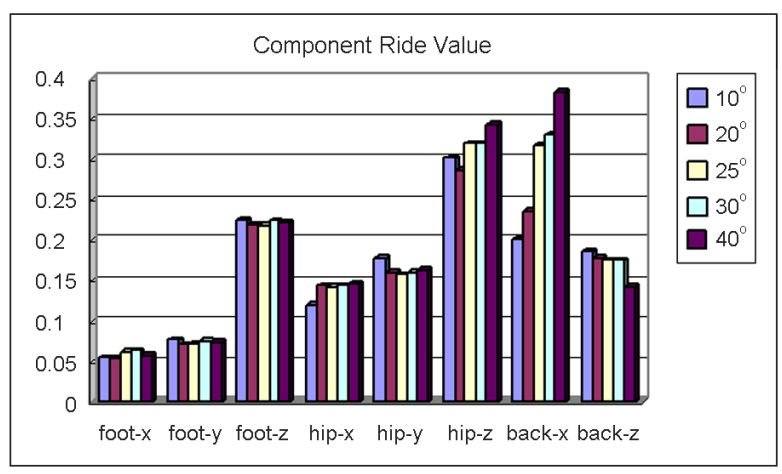

Figure 12. Component ride value with respect to backrest angle

Figure 11 and Figure 12. In Figure 11, the backrest angle increases the back $\mathrm{x}$-direction acceleration level and decreases the back z-direction acceleration level. But the back $\mathrm{x}$-direction acceleration contributes to ride value 
significantly than the back z-direction. In Figure 12, the $\mathrm{CRV}$ of the back $\mathrm{x}$-direction increases largely and decreases in the back z- direction with the backrest angle. We can see that back $x$-direction is more significant to the ride quality than hip z-direction when the angle was $40^{\circ}$.

\section{Discussion}

This study evaluated the ride qualities of the six passenger cars in 4 subjects on the highway and uneven road. The effects variation of driving velocity and driving posture on vibration were also investigated. Seat dynamics were investigated for the transmissibility in the seats and SEAT value. In the present experimental study, the ORV's of the vehicles were smaller while driving on the highway comparing with uneven road. On the uneven road the ORV's were similar to those of highway but the levels were increased by $75 \sim 98 \%$. The road surface unevenness is the main vibration source of vehicle dynamic response. The present finding was supported by the previous findings. Lin et al. 2006 observed that, where the asphalt uneven road surface had the worst ride quality and the long wave road surface had the best one. Fouladi et al. 2011 found that seat vibration will have more contribution from bumpy road comparing with smooth road. Paddan and Griffin, 2002 evaluated SEAT values of the 100 work vehicles in 14 categories and found that for most categories of vehicle, the average SEAT value was less than $100 \%$. In the present study all the vehicles had the SEAT value less than 1 or less than $100 \%$, so vibration was reduced by the seat. In terms of driving velocity, the present study showed that faster velocity lowers the SEAT value. This was because the velocity affected the higher frequency more than the lower frequency and the seat easily damps the high frequency vibration. At Lin et al. 2006, the subjects felt uncomfortable when the driving speed reaches $60 \mathrm{~km} / \mathrm{h}$ comparing with lower speed $30 \sim 40 \mathrm{~km} / \mathrm{h}$. The SEAT value is affected by the so many factors. The ORV and SEAT values were somewhat increased with the increase of the backrest angle. So when the backrest angle increases the ride quality in terms of the vibration get worse.

\section{Conclusion}

This study evaluated the ride qualities of six passenger cars with four subjects on the highway and uneven road. We evaluated the ride values (component ride value, overall ride value, SEAT value) and ranked the vehicles with the ride quality in terms of vibration exposed to the human. The smaller car had a first mode at the higher frequency and showed higher vibration level. SEAT values were mostly affected by the seat property not by vehicle. Based on SEAT values obtained, we ranked the luxury car seat had a best vibration reduction quality than other. The overall ride values increased proportionally and SEAT values somewhat decreased, when the driving velocity increased. When the backrest angle increased the overall ride value increased so the ride qualities get worse in view of vibration exposed to the human.

\section{References}

Amirouche, F.M., Xie, M. and Patwardhan, A., "Optimization of the Contact Damping and Stiffness Coefficients to Minimize Human Body Vibration", Journal of Biomechanical Engineering, 116(4), 413-420, 1994.

Berger, E. and Gilmore, B.J., "Seat Dynamic Parameters for Ride Quality," SAE Technical Paper 930115, 1993, doi: 10.4271/930115.

British Standards Institution, BS6841, Measurement and evaluation of human exposure to whole-body mechanical vibration and repeated shock, 1987.

Dupius, H. and Zerlett, G., The effects of whole-body vibration, SpringerVerlag, Berlin, 1986.

Fouladi, M.H., Nor, M.J.M., Inayatullah, O. and Ariffin, A.K., "Evaluation of seat vibration sources in driving condition using spectral analysis", Journal of Engineering Science, 6(3), 339-356, 2011.

Giacomin, J. and Bracco, R., "An experimental approach for the vibration optimisation of automotive seats", ATA 3rd Int. Conf. on Vehicle Comfort and Ergonomics, Bologna, Italy, March 29-31, 1995.

Griffin, M.J., Handbook of Human Vibration, Academic Press, London, 1990.

Griffin, M.J., "A comparison of standardized methods for predicting the hazards of Whole-body vibration and shocks", Journal of Sound and Vibration, 215(4), 883-914, 1998.

International Organization for Standardization, ISO2631, Mechanical vibration and shock - Evaluation of human exposure to whole-body vibration, 1997. 
Kelsey, J.L., "An epidemiological study of the relationship between occupations and acute herniated lumbar intervertebral discs", Int. Journal of Epidemiology, 4(3), 197-205, 1975.

Kim, T.H., Cho, Y.G., Yoon, Y.S. and Park, S.J., "Dynamic Ride Quality Investigation and DB of Ride Values for Passenger and RV Cars", SAE Technical Paper 2001-01-0384, 2001, doi:10.4271/2001-01-0384.

Lin, K.Y., Hwang, J.R., Chang, S.H., Fung, C.P. and Chang, J.M., "System Dynamics and Ride Quality Assessment of Automobile," $S A E$ Technical Paper 2006-01-1225, 2006, doi:10.4271/2006-01-1225.

McLain, R.F. and Weinstein, J.N., "Effects of whole body vibration on dorsal root ganglion neurons", Spine, 19(13), 1455-1461, 1994.

Meier, R.C., Otto, N.C., Pielemeir, W.J. and Jeyabalan, V., "The Ford vehicle vibration simulator for subjective testing", Sound and Vibration, 26-32, May 1998.

Nahvi, H., Fouladi, M.H. and Nor, M.J.M., "Evaluation of whole-body vibration and ride comfort in a passenger car", International Journal of Acoustics and Vibration, 14(3), 143-149, 2009.

Nahvi, H., Nor, M.J.M., Fouladi, M.H., and Abdullah, S., "Evaluating Automobile Road Vibrations Using BS 6841 and ISO 2631 Comfort Criteria", In: 1st Regional Conference on Vehicle Engineering \& Technology, Kuala Lumpur, Malaysia, 3-5 July 2006.

Necking, L.E., Dahlin, L.B., Friden, J., Lundborg, G., Lundstrom, R. and Thronell, L.E., "Vibration induced muscle injury", The Journal of Hand Surgery, 17B (3), 270-274, 1992.

Niekerk J.L., Pielemeir, W.J. and Greenberg, J.A., "The use of seat effective amplitude transmissibility (SEAT) values to predict dynamic seat comfort," Journal of sound and vibration, 260(5), 867-888, 2003.

Paddan, G.S. and Griffin, M.J., "Effects of seating on exposures to wholebody vibrations in vehicles", J. of Sound and Vibration, 253 (1), 215 $-241,2002$

Park, S.J. and Kim, C.B., "The Evaluation of Seating Comfort by the Objective Measures", SAE Technical Paper 970595, 1997, doi: $10.4271 / 970595$.

Park, S.J., Cheung, W.S., Cho, Y.G. and Yoon, Y.S., "Dynamic Ride Quality Investigation for Passenger Car", SAE Technical Paper 980660, 1998, doi: $10.4271 / 980660$.

Park, S.J., Lee, Y.S., Nahm, Y.E., Lee, J.W. and Kim, J.S., "Seating physical characteristics and subjective comfort: Design considerations", $S A E$ Technical Paper. 980653, 1998, doi: 10.4271/980653.

Park, S.J., Min, B.C., Lee, J.K. and Kang, E.S., "Development of the Evaluating System for Ride Comfort and Fatigue in Vehicle", $S A E$ Technical Paper 2001-01-0388, 2001, doi: 10.4271/2001-01-0388.

Parsons, K.C. and Griffin, M.J., "Methods for Predicting Passenger Vibration Discomfort", SAE Technical Paper 831029, 1983, doi: 10.4271/ 831029.

Pardko, F. and Lee, R., "Vibration Comfort Criteria", SAE Technical Paper 660139, 1966, doi: 10.4271/660139.
Reed, M.P., Kakishima, Y., Lee, N.S., Satio, M. and Schneider, L.Y., "An Investigation of Driver Discomfort and Related Seat Design Factors in Extended Driving", SAE Technical Paper 910117, 1991, doi: 10.4271/910117.

Staszewski, W.J. and Giacomin, J., "Application of the wavelet based FRF's to the analysis of non-stationary vehicle vibration", 15th Int. Modal Analysis Conf. IMAC, Orlando Florida, U.S.A., 1997.

Troup, J.D., "Drivers back pain and its prevention", Applied Ergonomics, 9(4), 207-214, 1978.

Valasek, M., Pelikan, J., Ulehla, J., Vaculin, O. and Steinbauer, P., "Experimental verification of correlation between objective and subjective of passenger car vibration comfort", Bulletin of Applied Mechanics, 4(15), 99-101, 2008

Wambold, J.C., "Vehicle Ride Quality Measurement and Analysis", SAE Technical Paper 861113, 1986, doi: 10.4871/861113.

\section{Author listings}

Se Jin Park: sjpark@kriss.re.kr

Highest degree: $\mathrm{Ph} . \mathrm{D}$

Position title: Director, Division of Convergence Technology, KRISS Areas of interest: Human Factors, Human Vibration, Human Sensibility Biomechanics, Human Computer Interaction (HCI)

Murali Subramaniyam: murali.subramaniyam@gmail.com

Highest degree: M.Tech (CIM)

Position title: Research Scholar, Center for Medical Metrology, KRISS Areas of interest: Biomechanics, DHM, CAD/CAM, Ergonomics, Human Vibration, Human Factors

Date Received : 2013-07-01

Date Revised :2013-08-02

Date Accepted : 2013-08-06 